\title{
BMJ
}

\section{Abuse of people with dementia by family carers: representative cross sectional survey}

\author{
Claudia Cooper, MRC research training fellow in health services research and health of the public, Amber \\ Selwood, honorary senior lecturer, Martin Blanchard, senior lecturer in old age psychiatry, Zuzana Walker, \\ senior lecturer in old age psychiatry, Robert Blizard, principal research fellow, Gill Livingston, professor of \\ older people's mental health
}

Department of Mental Health
Sciences, University College
London, W1W 7EJ

Correspondence to: C Cooper c.cooper@medsch.ucl.ac.uk

Cite this as: BMJ 2009;338:b155 doi:10.1136/bmj.b155

\section{ABSTRACT}

Objective To determine the prevalence of abusive behaviours by family carers of people with dementia. Design Representative cross sectional survey Setting Community mental health teams in Essex and London.

Participants 220 family carers of people newly referred to secondary psychiatric services with dementia who were living at home.

Main outcome measure Psychological and physical abuse (revised modified conflict tactics scale).

Results 115 (52\%, 95\% confidence interval 46\% to 59\%) carers reported some abusive behaviour and 74 (34\%, $27 \%$ to $40 \%$ ) reported important levels of abuse. Verbal abuse was most commonly reported. Only three (1.4\%) carers reported occasional physical abuse.

Conclusions Abusive behaviour by family carers towards people with dementia is common, with a third reporting important levels of abuse and half some abusive behaviour. We found few cases of physical or frequent abuse, although those with the most abusive behaviour may have been reluctant to report it.

\section{INTRODUCTION}

Elder abuse is a priority of both the UK government and the US federal government. ${ }^{2}$ In the UK it is defined as a single or repeated act or lack of appropriate action occurring within any relationship where there is an expectation of trust, which causes harm or distress to an older person. ${ }^{1}$

In the UK the government is consulting about a revision of the current policy for safeguarding vulnerable adults. ${ }^{3}$ This review is entirely focused on preventing abuse by paid carers, suggesting that abuse is confined to the formal care system. This is in line with the 2004 statement by the House of Commons select committee that "few incidents of abuse are committed by loving, supportive people who have lashed out." Abuse can be psychological, financial, sexual, physical, or by neglect. Despite the select committee's contention, many family carers for people with dementia report acting abusively when asked and might see no alternative way to manage the situation and be unaware that their behaviour would be defined as abusive. ${ }^{45}$ No studies of abusive behaviours in representative populations of family carers currently exist, but our systematic review found that the prevalence of elder abuse reported by family carers ranged from $12-55 \% .{ }^{6}$ Few of these studies used instruments with known psychometric properties. ${ }^{6}$ We determined the prevalence of abuse by family carers of people with dementia in a representative population of care recipients referred to secondary care.

\section{METHODS}

We recruited family carers of people with a clinical diagnosis of dementia who were living at home and referred to community mental health teams covering London and Essex (which included inner city, suburban, and rural areas).

A researcher attended team meetings and reviewed the notes of all people consecutively referred to the team after being assessed. The clinical team initially contacted potentially eligible family carers (defined as providing care for four or more hours a week), and gave them an information sheet on the study. One week later a researcher telephoned the carers, unless they had asked not to be contacted. Interviews took place at a time and place convenient to the carer, usually their home.

Participants gave written informed consent. The information sheet specified that "we respect confidentiality but cannot keep it a secret if anyone is being seriously harmed." The care recipients were asked for consent to access their medical notes but not interviewed. When they lacked capacity to consent (judged from psychiatrist and carer reports), we asked the carers whether they thought that the care recipient would have agreed when they had capacity. Three experienced psychiatrists carried out interviews between January 2007 and April 2008.

\section{Measures}

We collected data on the age of the carer and care recipient, sex, ethnicity, qualifications, the carer's relationship to the care recipient (spouse, child, other), if the carer lived with the care recipient, and whether the carer worked. Our main outcome measure was abuse 
using the validated modified conflict tactics scale, completed by the carer. ${ }^{57}$ This scale asks how often in the past three months the carers had acted in each of five psychologically and five physically abusive ways towards the care recipient, on a Likert scale from 0 (never) to 4 (all the time). A score of 2 or more (sometimes) on any question denotes important abuse. The scale has subscales for psychological and physical abuse. From the care recipient's medical notes we also obtained the most recent mini-mental state examination score and drugs. Carers were asked about the care recipient's neuropsychiatric symptoms using the neuropsychiatric inventory. ${ }^{8}$

\section{Data analysis}

Using appropriate summary statistics we reported the sociodemographic characteristics of the sample and the illness characteristics of the care recipient. We also reported the proportion of carers meeting criteria for abuse (caseness), and the proportion who indicated that each of the 10 behaviours occurred "at least sometimes." We used online software to calculate 95\% confidence intervals. ${ }^{9}$

\section{RESULTS}

Overall, 220 of 319 (69\%) eligible carers participated; 98 refused or were not contactable. Participants and non-participants did not differ for sex of the carer and care recipient $\left(\chi^{2}=1.3, \mathrm{P}=0.26 ; \chi^{2}=0.0, \mathrm{P}=1.00\right)$, whether they lived together $\left(\chi^{2}=2.2, \mathrm{P}=0.14\right)$, or the relationship (partner, child, other) between them $\left(\chi^{2}=2.7, \mathrm{P}=0.26\right)$.

One hundred and forty four $(66 \%)$ family carers were women, $182(83 \%)$ were of white UK ethnicity, 157 $(71 \%)$ were living with a partner, and 118 (54\%) were living with the care recipient. Their mean age was 61.7 (SD 13.1) years (range 24-92 years). One hundred and twenty $(56 \%)$ were caring for a parent, $72(33 \%)$ for a spouse, and $28(13 \%)$ for another relative or friend. Ninety $(41 \%)$ had remained in education until age 18 , and $86(39 \%)$ were in full time or part time employment. One hundred and fifty nine $(72 \%)$ of the care

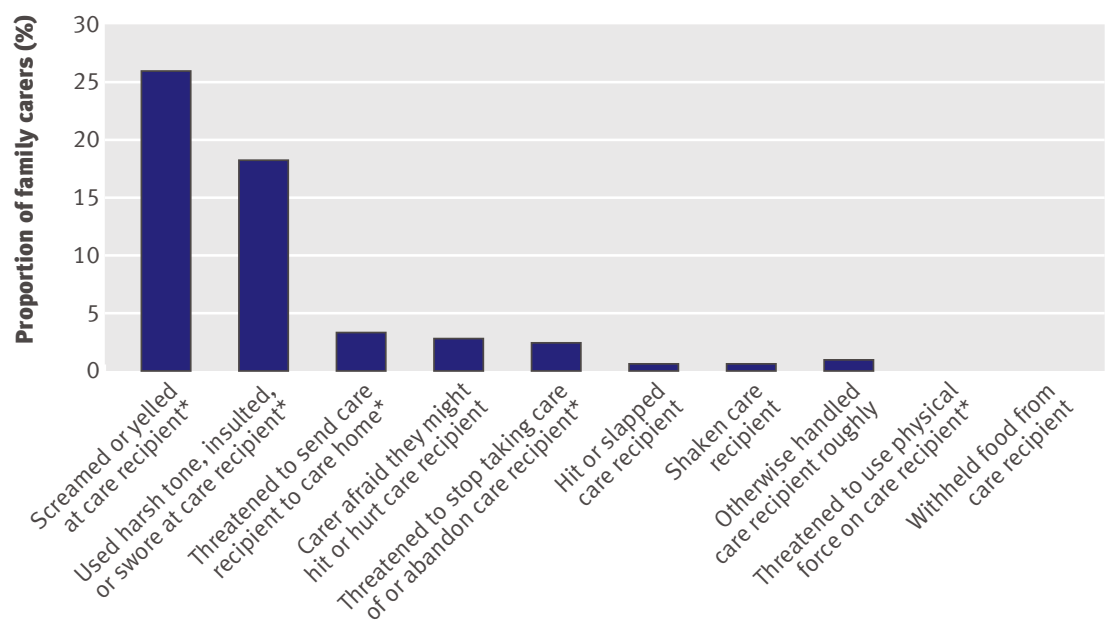

Proportion of family carers reporting each abusive behaviour occurring "at least sometimes" in previous three months. *Scale item for psychological abuse; remainder for physical abuse recipients were women (mean age of 81.6 (SD 7.8) years, range 58-99 years). Mini-mental state examination scores were available for 211 care recipients (mean score 18.4 (SD 7.0), range 0-29). The mean neuropsychiatric inventory score was 18.3 (SD 1.1, range 0-75). According to the family carers, the care recipients had experienced problems with their memory for a mean of 33.7 (SD 38.9) months (range 0-300).

\section{Prevalence of abusive behaviour}

In total, $115(52 \%, 95 \%$ confidence interval $46 \%$ to $59 \%$ ) carers reported some abusive behaviour. Total scores on the abuse instrument ranged from 0 to 11 , with a median score of 1 (interquartile range $0-2$ ). Seventy four (34\%, 27\% to 40\%) family carers reported abusive behaviours occurring "at least sometimes" in the past three months (figure), the threshold used in this study to denote important abuse. The verbal abuse items were most commonly reported. Only one carer stated that any of the abusive behaviours were taking place "most of the time," and none that any abuse was happening "all of the time."

Seventy two (33\%, 27\% to 39\%) carers reported that psychological abuse occurred sometimes and eight $(4 \%, 1 \%$ to $6 \%)$ that physical abuse occurred sometimes. Seven $(3 \%)$ of the cases of physical abuse was because the carer reported that they were sometimes afraid that they might hit or hurt the care recipient. Only three $(1 \%)$ carers reported that actual physical abuse sometimes occurred. Four people said "almost never" (subthreshold for case level) to physical abuse items of whom three were "afraid that they might hit or hurt" and one reported "almost never" handling the care recipient roughly.

\section{DISCUSSION}

Family carers commonly reported acting abusively towards people with dementia, with a third scoring equivalent to cases of abuse. This suggests that any policy for safeguarding vulnerable adults must consider strategies directed towards families who provide most care for older people, rather than exclusively concentrating on formal carers.

The prevalence of elder abuse reported by family carers in previous studies has ranged from $12-55 \%,{ }^{6}$ with some of the variation due to differences in definitions of what constitutes a case of abuse. Different definitions of abuse would have changed our figures for prevalence as half of family carers interviewed in our study reported abusive behaviour, mostly verbal, whereas few reported frequent or physical abuse. It is unsurprising that disagreement exists about what form of behaviour constitutes elder abuse and what is part of normal family relationships. In one US study, for example, $5 \%$ of older couples, and a higher percentage of younger couples, reported physical violence within their relationship over the previous year. ${ }^{10}$ Abusive behaviour may be a continuation of an earlier, possibly mutually aggressive relationship, ${ }^{10}$ which could become abusive if the care recipient no longer has the 


\section{WHAT IS ALREADY KNOWN ON THIS TOPIC}

People with dementia are particularly vulnerable to abuse

Many family carers of people with dementia report acting abusively

Professionals are reluctant to ask about elder abuse

\section{WHAT THIS STUDY ADDS}

A third of family carers reported significant abusive behaviour towards people with dementia in a secondary care setting

Most carers reported some abusive behaviour but few reported more serious and physical abuse

Elder abuse may be more realistically considered on a spectrum rather than as an "all or nothing" phenomenon comprise disproportionately those with a new diagnosis or with acute problems. Thus our population was less cognitively impaired than the population with dementia. ${ }^{13}$ Care recipients may have had untreated neuropsychiatric symptoms (although the mean score was almost identical to that of a previous representative sample)..$^{14}$

\section{Conclusions}

Most family carers reported some abusive behaviour, and a third reported important levels of abuse. We found few cases of physical or frequent abuse. We suggest that any policy for safeguarding vulnerable adults must consider strategies directed towards families who provide the majority of care for older people, rather than exclusively formal carers. Considering elder abuse as a spectrum of behaviour rather than an "all or nothing" phenomenon could help professionals to feel more able to ask about it and therefore offer appropriate help

We thank the carers and patients who took part in the study, Colm Owens for doing some of the interviews, the Alzheimer's Society (Islington branch), Shirley Nurock for her assistance in developing the study, Camden and Islington Foundation Trust, North Essex Partnership Foundation NHS Trust, and North East London NHS Foundation Trust; in particular Ruth Allen, Suzanne Joels, Vincent Kirchner, and Tim Stevens. Contributors: CC, GL, and MB conceived and designed the study. CC analysed the data and drafted the manuscript. She is guarantor. All authors were involved in the interpretation of the data, revised the manuscript critically for important intellectual content, and approved the version to be published.

Funding: This research was funded by a research training fellowship awarded to CC by the Medical Research Council. The authors' work was carried out independently of the funders.

Competing interests: None declared.

Ethical approval: This study was approved by the London multicentre research ethics committee.

1 House of Commons Health Select Committee. Elder abuse. No 2. London: Stationery Office, 2004.

2 Administration on Aging. Elders rights and resources: elder abuse. 2008.www.aoa.gov/eldfam/elder_rights/Elder_Abuse/ Elder Abuse.aspx

3 Department of Health. Consultation on the review of the no secrets guidance: invitation to the local safeguarding partnerships. 2008. www.dh.gov.uk/en/Publicationsandstatistics/Lettersandcirculars/ Dearcolleagueletters/DH_089375.

4 Williamson GM, Shaffer DR. Relationship quality and potentially harmful behaviors by spousal caregivers: how we were then, how we are now. Psychol Aging 2001:16:217-26.

5 Beach S, Schulz R, Williamson G, Miller L, Weiner M, Lance C. Risk factors for potentially harmful informal caregiver behavior. J Am Geriatr Soc 2005;53:255-61.

6 Cooper C, Selwood A, Livingston G. The prevalence of elder abuse and neglect: a systematic review. Age Ageing 2008;37:151-60.

7 Cooper C, Manela M, Katona C, Livingston G. Screening for elder abuse in dementia in the LASER-AD study: prevalence, correlates and validation of instruments. Int J Geriatr Psychiatry 2008;23:283-8.

8 Cummings JL. The neuropsychiatric inventory: assessing psychopathology in dementia patients. Neurology 1997;48:S10-116.

9 Creative Research Systems. Sample size calculator. 2008. www. surveysystem.com/sscalc.htm.

10 Harris S. For better or worse: spouse abuse grown old. J Elder Abuse Negl 1996;8:1-33.

11 Oswald RA, Jogerst GJ, Daly JM, Bentler SE. lowa family physician's reporting of elder abuse. J Elder Abuse Negl 2004;16:75-88.

12 Goode S. "The splendor of little girls": social constructions of paedophiles and child sexual abuse. Winchester, Hampshire: University of Winchester, 2006.

13 Fratiglioni L. Epidemiology. In: Wimo A, Jonsson B, Karlsson G, Winblad B, eds. Health economics of dementia. New York: Wiley, 1998:13-31.

14 Ryu SH, Katona C, Rive B, Livingston G. Persistence of and changes in neuropsychiatric symptoms in Alzheimer disease over 6 months: the LASER-AD study. Am J Geriatr Psychiatry 2005;13:976-83.

Accepted: 4 November 2008 